\title{
Gross profit in relation to operational account analysis
}

\author{
B. VAN BOVEN and J. KAMMINGA \\ Proefstation voor de Akker- en Weidebouw (P.A.W.), Wageningen, Netherlands
}

By operational account analysis is meant the production plan for a farm. This means that in so far as concerns the technical production possibilities and the total outputs of combinations of these possibilities, the limits are set by the characteristics of the farm itself. Thus the following can be determined:

What can be produced technically and how it can be done;

The maximum extent to which it can be produced.

Within these data the operational account analysis attempts to determine:

What will be produced and to what extent.

This involves balancing the given production possibilities for a given farm.

There are various methods of drawing up a production programme: the traditional budget, the gross-margin method, the programme-planning method and linear programming. Applying these in the order listed leads to a closer approximation of optimal planning. Except for the traditional budget all methods make use of the term gross profit. An optimal plan is assumed to be reached when the sum of gross profits of the various enterprises is at a maximum within the prevailing limitations.

In this case, gross profit is often described as the gross output minus attributable costs, or sometimes also minus allocated costs. These definitions of the term gross profit are rather unfortunate, for attributable costs are costs applying to a particular product or production process. Accordingly, allowed and non-allowed costs to be included in the gross profit are not mentioned here.

Nor is the situation improved by the use of the term allocated costs, for except in case of common costs all expenses are primarily allocated, either directly or indirectly, on the basis of certain arbitrary criteria of allocation.

A second description of the term gross profit is gross output minus variable costs. The classification of costs in variable and fixed costs is due to the fact that costs will react differently when the production is increased or decreased. In these cases, there are costs that continually vary with changes in the production rate and costs varying with smaller or larger intervals. The production rate is the amount of output per time unit. The first group comprises sowing seed, fodder, etc.; the second group includes certain implements and, with still larger intervals, farmhouses.

The cost of farm buildings in this instance may be considered as fixed when compared with the costs of implements, sowing seed, etc. The latter, however, are variable with regard to the farmhouses.

During intervals in which the cost of implements has not changed, these costs may be considered fixed costs as compared with all other continually varying costs. Generally speaking, it may be stated that more and more costs will be variable as the production increases. The relativity of the difference between variable and fixed costs

Received for publication 19th February, 1964. 
makes a correct interpretation of the term gross profit very difficult and also gives rose to misunderstandings in practice.

Before treating this subject in greater detail, it will be wise to pay some attention to the terms direct and indirect costs, on the one hand, because the gross profit is sometimes defined by the aid of these; and, on the other hand, because direct and variable costs are often wrongly segregated.

Direct costs are costs associated with an immediate yield of a certain amount of product. There is no direct relation with indirect costs. These costs first yield one or more results which afterwards lead to a quantity of product. The classification of costs into variable and fixed costs is confusing, because direct costs may also vary continually with changes in the rates of output. This coincidence, however, need not lead to confusion, for each of the cost classifications serves a particular purpose. The classification into variable and fixed costs is used to denote the reaction of costs to changes in the rate of production. This is a distinction of a dynamic kind. Direct and indirect costs, however, have a static nature in that costs are detailed to the various products. In the case of homogeneous mass production even this classification is useless.

Clearly, the distinction between direct and indirect costs is irrelevant to the concept of gross profit as used in operational account analysis, for it does not involve specification of certain costs but is merely used to determine the rate of output of the enterprise. The distinction between variable and fixed costs is relevant in this context. When used for this purpose, however, these terms should be more precisely defined.

In view of the purpose of planning (viz. an answer to the question "what and how much"), it is necessary to draw up the gross profits in such a way as to make a fair comparison between the relevant courses of action. But what is a fair comparison?

In the first place, this means that the time unit related to the gross profits should be the same for all activities.

Furthermore, only those costs should be deducted from the gross revenue of an enterprise that are relevant to that activity, in contradistinction to costs that apply to more than one enterprise. These costs cannot be fairly apportioned because the actual volume of each activity still has to be determined. This is not possible with gross profits per unit of activity.

Thirdly, only those costs relating to factors used solely in one production process may be taken into account. This also is a condition for a fair comparison in apportioning costs incurred in more than one production process. These can only be determined when the "what and how much" have been decided upon.

In summarizing the preceding, the term gross profit may be described as the gross revenue minus the costs related to one activity only and to factors used solely in one production process. For a fair comparison the time unit related to the gross profits should be the same.

In terms of the classification into variable and fixed costs the definition of the term gross profit means that only continually varying costs may be included.

This also means that with each change in the costs that do not vary continually there will be a new planning situation and a new appropriate optimal plan. 